\title{
Nanocrystalline Nd-Fe-B Alloys for Polymer-Bonded Magnets Production
}

\author{
Aleksandar Grujić,, ${ }^{1}$ Vladan Ćosović, ${ }^{1}$ Aleksandar Ćosović, ${ }^{2}$ and Jasna Stajić-Trošić1 \\ ${ }^{1}$ Institute of Chemistry, Technology and Metallurgy, University of Belgrade, Njegoseva 12, 11000 Belgrade, Serbia \\ ${ }^{2}$ Institute for Technology of Nuclear and Other Mineral Raw Materials, Franse d' Eperea 86, 11000 Belgrade, Serbia \\ Correspondence should be addressed to Aleksandar Grujić, gruja@tmf.bg.ac.rs
}

Received 30 April 2012; Accepted 21 May 2012

Academic Editors: J. Ding and J. J. Suñol

Copyright ( 2012 Aleksandar Grujić et al. This is an open access article distributed under the Creative Commons Attribution License, which permits unrestricted use, distribution, and reproduction in any medium, provided the original work is properly cited.

\begin{abstract}
This study presents how different nanostructures of starting Nd-Fe-B particles have influence on magnetic properties of polymerbonded Nd-Fe-B materials. Two types of nanocrystalline Nd-Fe-B alloys were used for polymer composite production by compression molding technique. The particles with low neodymium content (Nd-low) have nanocomposite structure with small exchange coupling effect between hard and soft magnetic phase. In other hand, practically monophase hard magnetic structure of Nd-Fe-B particles with stoichiometric neodymium content (Nd-stoich) shows improved magnetic properties. With increasing concentration of polymer matrix, the coercivity $\left(H_{\mathrm{cb}}\right)$, remanence $\left(B_{r}\right)$, and maximum energy product $\left((B H)_{\max }\right)$ decrease more prominenty for composites with stoichiometric $\mathrm{Nd}-\mathrm{Fe}-\mathrm{B}$ content.
\end{abstract}

\section{Introduction}

The Nd-Fe-B magnetic materials as one of the most superior magnets have wide range of applications in different branches like: power generation, transportation, electronics, and automotive industry $[1,2]$. Moreover, Nd-Fe-B magnetic alloys are very suitable and are commonly used in combination with various types of polymer matrices for bonded magnet production $[3,4]$.

Depending on stoichiometry, that is, neodymium content, three different types of Nd-Fe-B alloys can be distinguished, low neodymium or nanocomposite alloys, stoichiometric or monophase alloys, and decoupled or neodymium rich alloys [5]. Each type is characterized by distinctive structure and magnetic properties that determine their field of application. While low neodymium and stoichiometric alloys are suitable for bonded magnet production neodymium rich alloys are more used for high-coercive permanent magnet production.

The structure of the nanocomposite Nd-Fe-B alloy with $\mathrm{Nd}$ low content is composed of a mixture of magnetically hard $\mathrm{Nd}_{2} \mathrm{Fe}_{14} \mathrm{~B}$ and soft $\mathrm{Fe}_{3} \mathrm{~B}, \alpha$-Fe or $\mathrm{Fe}_{3} \mathrm{~B} / \alpha$-Fe phases. The exchange coupling that occurs between the grains of hard magnetic phase and the soft magnetic Fe-rich grains explains the total magnetic property [5-8]. It was found that this intergranular interaction, which has significant influence on the magnetic properties, becomes more pronounced on nanoscale. The main condition for obtaining nanocomposite structure is uniform distribution of soft and hard phase in magnetic matrix, where size of crystal grains should be less than $40 \mathrm{~nm}[6,7]$. Hence, the significant research efforts were put into optimization of the nanostructure of these alloys. Conversely, the stoichiometric Nd-Fe-B alloy has an almost monophase composition with dominant amount of $\mathrm{Nd}_{2} \mathrm{Fe}_{14} \mathrm{~B}$ phase. This type of alloys is characterized by intergranular exchange coupling between the grains of the same $\mathrm{Nd}_{2} \mathrm{Fe}_{14} \mathrm{~B}$ hard magnetic phase $[9,10]$ and exhibit high-quality magnetic performance with high value of maximum energy product. Full characterization and analysis of different Nd-Fe-B structures were reported previously $[11,12]$. Comparisons between nanostructures with various content of neodymium clearly show the differences between two investigated structures [13].

In this study, magnetic particles are introduced into epoxy polymer in order to produce bonded magnetic material with applicable magnetic and dynamic mechanical 
TABLE 1: Magnetic properties of the starting Nd-Fe-B alloys.

\begin{tabular}{lccccc}
\hline Alloy & Name & $B_{r}[\mathrm{~T}]$ & $H_{\mathrm{cb}}[\mathrm{kA} / \mathrm{m}]$ & $H_{\mathrm{cj}}[\mathrm{kA} / \mathrm{m}]$ & $(B H)_{\max }\left[\mathrm{kJ} / \mathrm{m}^{3}\right]$ \\
\hline NM-L & Nd low & 1.09 & 214.9 & 222.8 & 85.1 \\
NM-B & Nd stoich & 0.82 & 477.5 & 692.3 & 104.2 \\
\hline
\end{tabular}

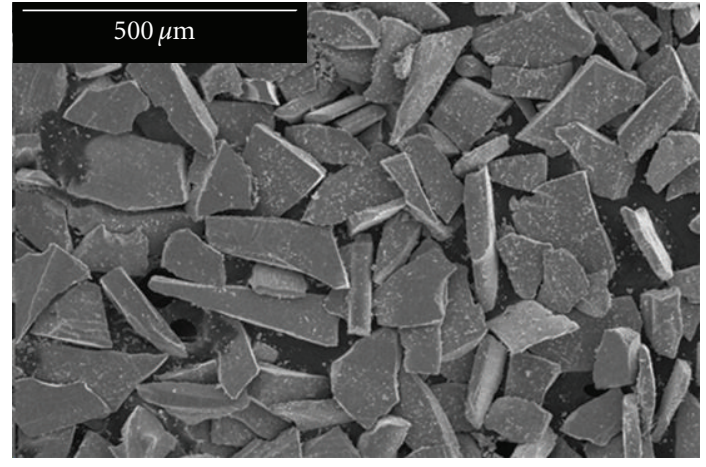

(a)

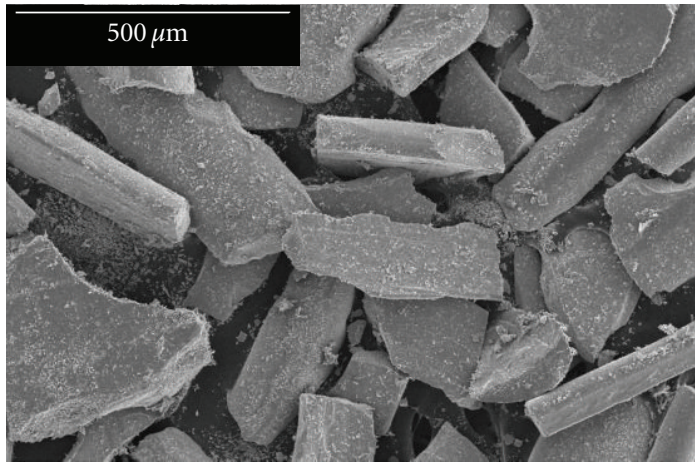

(b)

FIgURE 1: SEM micrographs of the (a) Nd-low and (b) Nd-stoich Nd-Fe-B alloy.

properties. A compression molding method, as one of the most common method for polymer composite production, is used. As the parameters of synthesis have influence on package density, mechanical and magnetic properties of final composite materials [14], this study presents how different nanostructures of starting $\mathrm{Nd}-\mathrm{Fe}-\mathrm{B}$ particles influence magnetic properties of polymer-bonded $\mathrm{Nd}-\mathrm{Fe}-\mathrm{B}$ materials.

\section{Experimental}

2.1. Starting Materials. The Nd-Fe-B magnetic powders with reduced (Nd-low) and stoichiometric (Nd-stoich) neodymium content, brand named as NM-L and NM-B, respectively, used in this study were supplied by Ningbo Haixin Co. Ltd, China. Magnetic properties of the used magnetic alloys are given in Table 1.

The chemical composition of starting Nd-low alloy is: Nd: 12 mass \%, Pr: 0.2 mass \%, B: 4.2 mass \%, Al: 0.3 mass \%, and Fe: balance. The chemical composition of starting Ndsteh alloy is: $\mathrm{Nd}$ : $21-25$ mass $\%$, Co: $3-5$ mass $\%, \mathrm{~B}<1.5$ mass \%, Zr: 3-5 mass \%, Fe: balance.

Thermosetting epoxy system that is a combination of liquid mixture of bisphenol $\mathrm{A}$ and bisphenol $\mathrm{F}$ resins and cross linking agent (hardener) which cures fully at room temperature is used as polymer matrix. The cured pure epoxy resin has density $\sim 1.2 \mathrm{~g} / \mathrm{cm}^{3}$, tensile strength $\sim 58 \mathrm{MPa}$, elongation $\sim 2.8 \%$, compression strength $\sim 96 \mathrm{MPa}$, and flexural strength $\sim 78 \mathrm{MPa}$.

2.2. Synthesis. Composites with varied content of the Nd-Fe$\mathrm{B}$ particles in the epoxy matrix ranging from 15 to $95 \mathrm{wt} \%$ were produced by compression molding method under a pressure of $4 \mathrm{MPa}$ at room temperature, using a lab scale compression molding press. The molded samples were then allowed to cure under a molding pressure for about 24 hours.

2.3. Characterisation. Morphology of the starting alloys was observed using JEOL JSM-5800 Scanning Electron Microscope (SEM). The nanostructure of the starting alloys was analyzed by means of transmission electron microscopy (TEM). For the preparation of the samples for TEM investigation, the H-bar focused ion beam (FIB) technique was used [15]. Phase composition of the investigated alloys was determined by X-ray diffractometry (XRD) by X'Pert PRO MPD multipurpose XRD system from PANanalytical using Co $\mathrm{K} \alpha$ radiation. Magnetic properties of the starting alloys and composites were measured at ambient temperature using the Quantum Design MPMS 5XL Superconducting Quantum Interference Device (SQUID) magnetometer with magnetic field strength in the range -5 up to $5 \mathrm{~T}$.

\section{Results and Discussion}

The starting $\mathrm{Nd}-\mathrm{Fe}-\mathrm{B}$ alloys are in a form of powders consisting of plate-like particles which are widely used for polymer-bonded magnet production $[3,16]$. Such particle shape is favorable considering that the plate-like particles would result in higher packing density under the optimal compression conditions [17]. SEM micrographs illustrating morphology of the used alloys are presented in Figure 1.

Although the investigated $\mathrm{Nd}-\mathrm{Fe}-\mathrm{B}$ alloys appear to be very similar, the real difference between them becomes apparent when comparing the nanostructures, phase compositions, and magnetic properties. Taking into account that it is widely recognized that the properties of nanocrystalline $\mathrm{Nd}-\mathrm{Fe}-\mathrm{B}$ alloys are size dependent and known to be very sensitive to nanostructure and phase composition, the used 


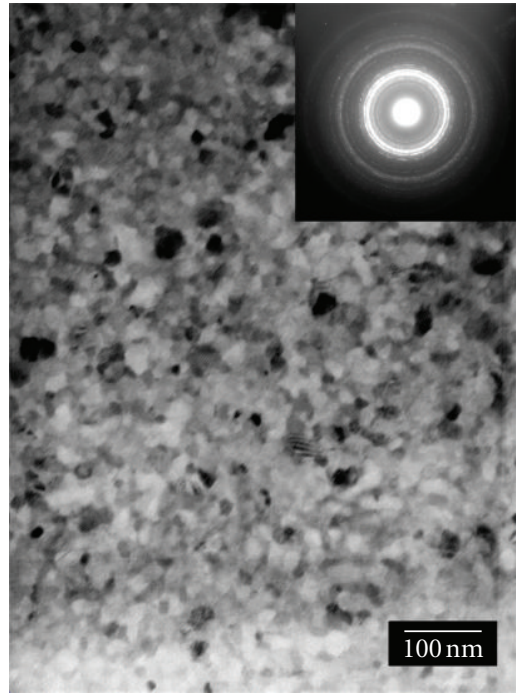

(a)

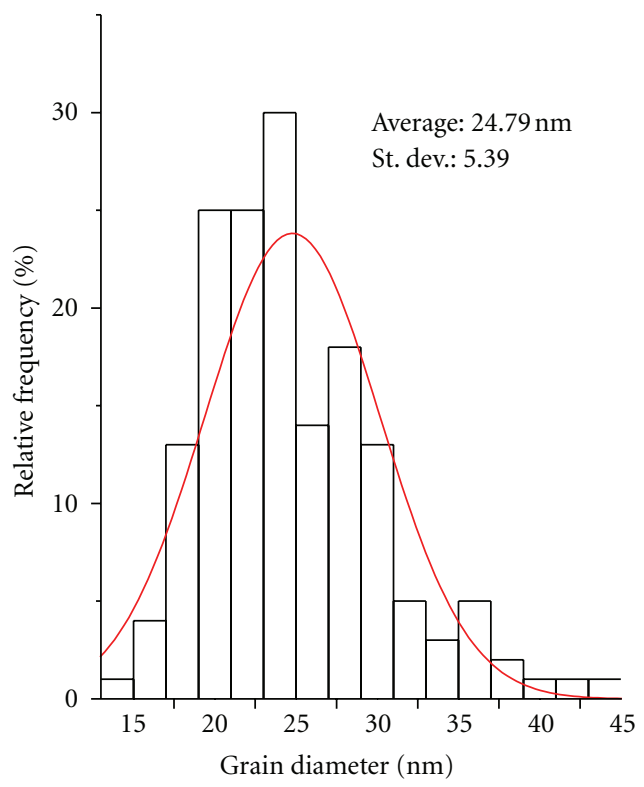

(b)

FIGURE 2: Bright field TEM micrograph of the Nd-low alloy microstructure with the corresponding crystal grain size distribution.

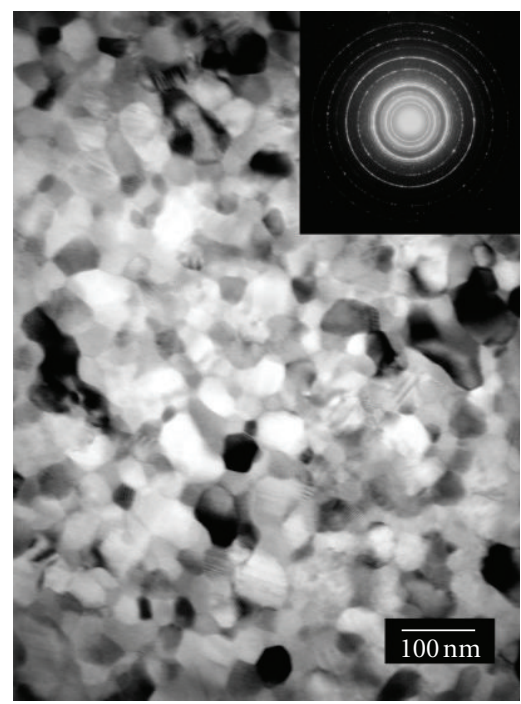

(a)

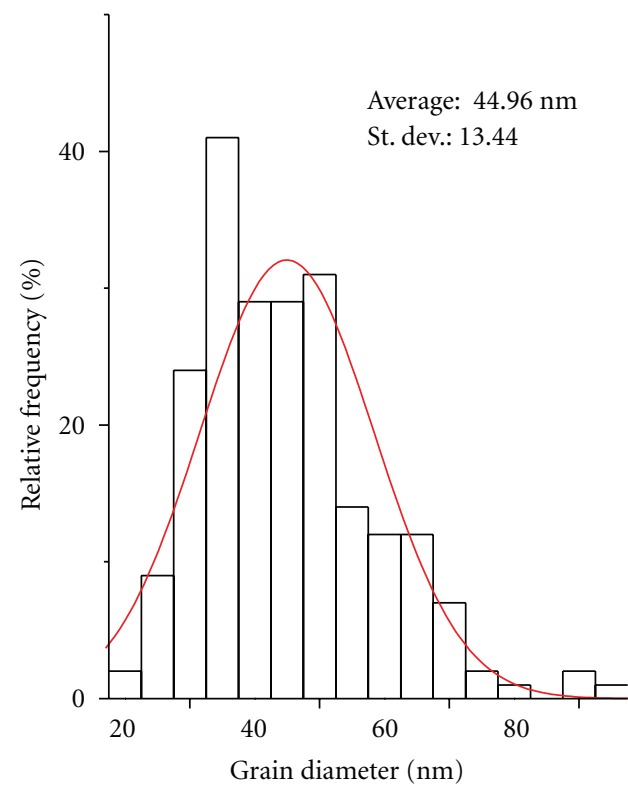

(b)

FIGURE 3: Bright field TEM micrograph of the Nd-stoich alloy microstructure with the corresponding crystal grain size distribution.

Nd-low and Nd-stoich alloys were further analyzed using TEM and XRD techniques.

The obtained bright field TEM micrographs (Figures 2 and 3), illustrating the nanostructure of the studied Nd-Fe$\mathrm{B}$ alloys, confirm the nanocrystalline structure of the both analyzed alloys. The obtained electron diffraction patterns show very high density of diffraction rings, due to which reliable identification of the present phases was not possible.
As it can be seen from Figure 2, the average crystal grain size of the Nd-low alloy, determined by TEM analysis, is below $30 \mathrm{~nm}$, while the corresponding grain size distribution indicates that the majority of grains have sizes in the range 20-30 nm.

In contrast, the TEM image of the Nd-stoich alloy (Figure 3) reveals nanostructure composed of comparatively larger crystal grains, almost double the size. The mean grain 


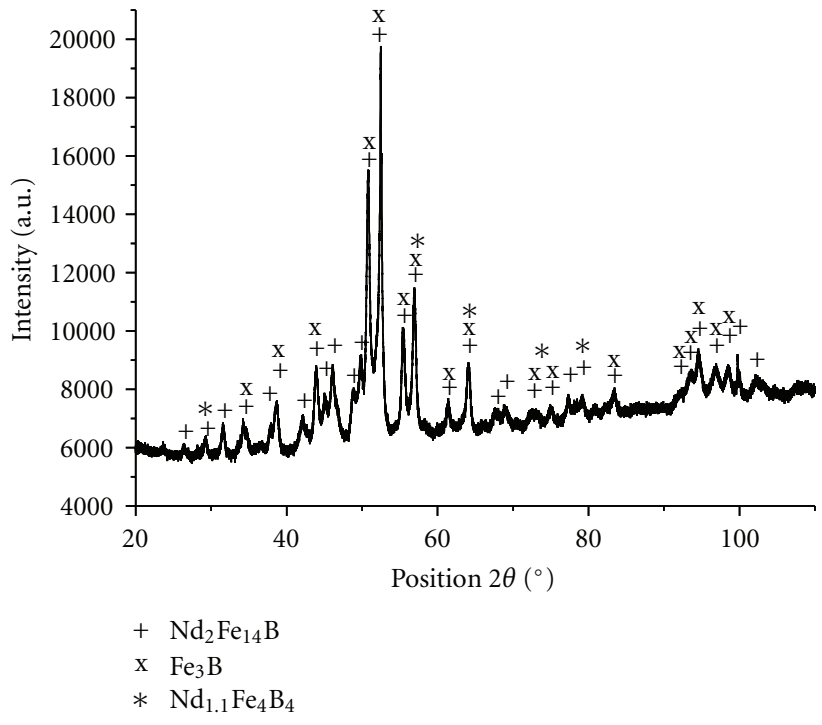

(a)

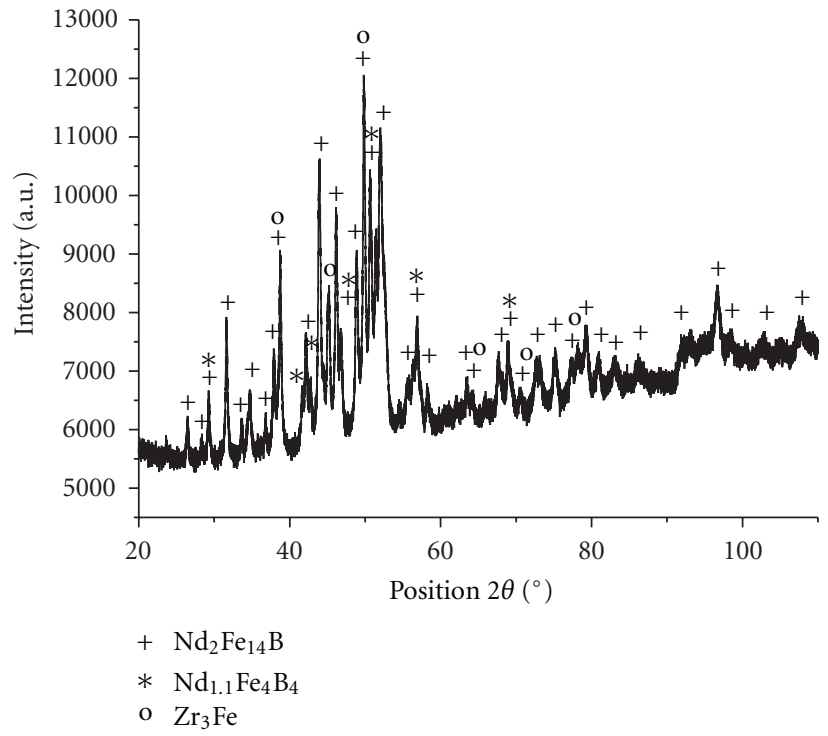

(b)

FIgURE 4: X-ray diffraction patterns of the (a) Nd-low and (b) Nd-stoich alloy.

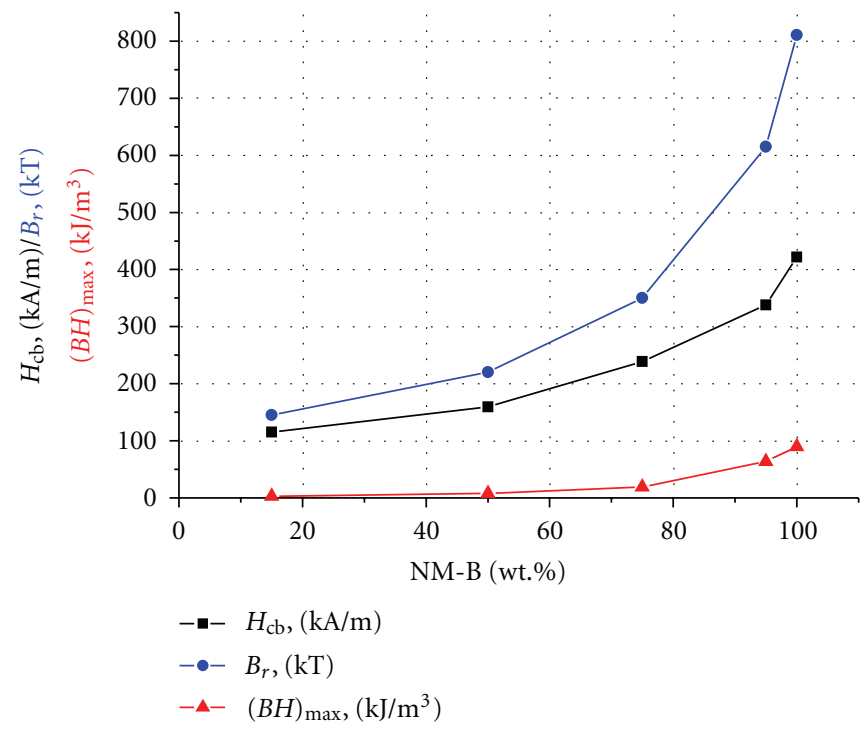

(a)

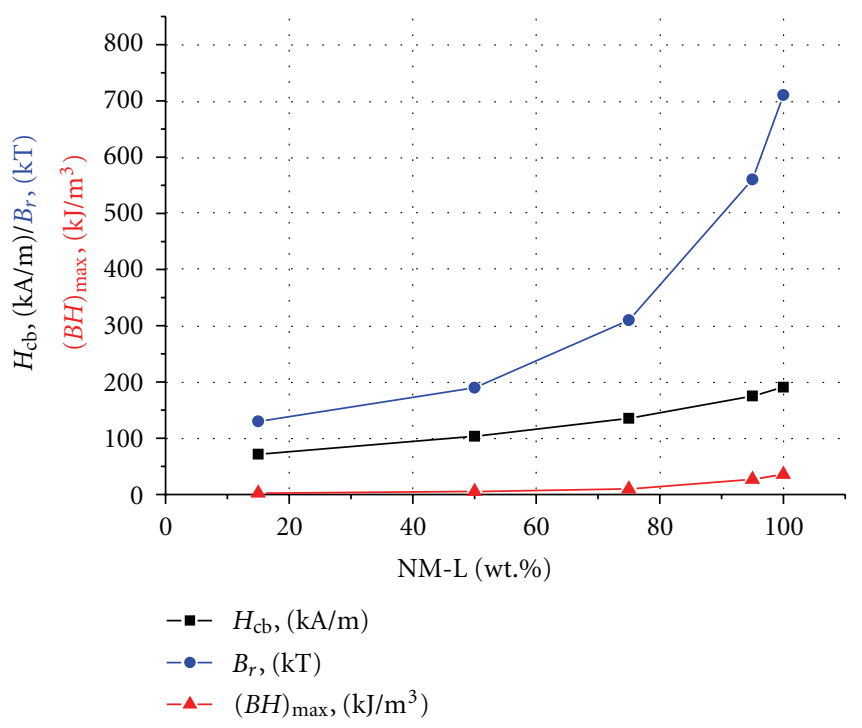

(b)

Figure 5: Magnetic properties of the obtained polymer-bonded composites.

size is estimated to about $45 \mathrm{~nm}$, while the corresponding grain size distribution demonstrates that the majority of grains have sizes in the range $30-60 \mathrm{~nm}$.

The phase composition of both used alloys are validated by XRD analysis and presented in Figure 4. As expected, the Nd-low alloy represents a mixture of soft and hard magnetic phases. The identified phases are calculated as follows: $38 \%$ $\mathrm{Nd}_{2} \mathrm{Fe}_{14} \mathrm{~B}, 58 \% \mathrm{Fe}_{3} \mathrm{~B}, 4 \% \mathrm{Nd}_{1.1} \mathrm{Fe}_{4} \mathrm{~B}_{4}$, and set of $\mathrm{Fe}_{2} \mathrm{~B}$, $\mathrm{Fe}(\mathrm{Nd}, \mathrm{B})$ and $\alpha$-Fe in traces. Comparably, the $\mathrm{Nd}$-stoich alloy consists predominantly of hard magnetic $\mathrm{Nd}_{2} \mathrm{Fe}_{14} \mathrm{~B}$ phase (around $92 \%$ ), $5 \% \mathrm{Nd}_{1.1} \mathrm{Fe}_{4} \mathrm{~B}_{4}$ and $3 \% \mathrm{Fe}$-para phase.

Taking into consideration shape, mechanical and physical properties of the used $\mathrm{Nd}-\mathrm{Fe}-\mathrm{B}$ alloys it can be assumed that dynamic mechanical properties of these composites are similar. Previously studied polymer magnetic composites $[18,19]$ suggest that there is no significant deviations in dynamic mechanical properties between composites that contain low and stoichiometric Nd-Fe-B fillers in the same type of polymer matrix. Glass transition temperatures and temperatures of decomposition strongly depend on used polymer matrix while changes of enthalpy depend on concentration of magnetic filler. Nevertheless, shifting of the $T_{g}$ is possible by coating the particles with coupling agents and using the nanosized magnetic powders.

Optimal process parameters, particle distribution, particle shape and size, packing density, and good adhesion 
between Nd-Fe-B particles and a polymer matrix are all essential for structure and magnetic properties of the final composite material. Generally speaking, a packing density of composites increases with the rising Nd-Fe-B filler content in polymer matrix [14]. Alternatively, the packing density can be increased by mixing powder fractions of different particle size and size distribution. Hence, the resulting optimized powder mixture will have small particles filling the interparticle volume of packing of larger particles.

On the other hand, magnetic properties of the polymerbonded composites are directly related to amount and type of magnetic filler. Using the different amounts of the Nd-FeB magnetic filler for polymer-bonded composite production will result in changeable magnetic properties of a final magnet. Magnetic properties (remanence, coercivity, and maximum energy product) of the obtained polymer-bonded composites in a function of Nd-low and Nd-stoich magnetic filler content are presented in Figure 5. As expected, Figure 5 shows increase of magnetic properties for the both types of composites with increase of $\mathrm{Nd} \mathrm{Fe-B} \mathrm{content.} \mathrm{A} \mathrm{hysteresis}$ loops of various $\mathrm{Nd}-\mathrm{Fe}-\mathrm{B} / \mathrm{epoxy}$ composite compositions is reported elsewhere $[18,19]$.

From Figure 5 it is also evident that for pure Nd-FeB particles $(100 \mathrm{wt} \%) \mathrm{Nd}$-stoich alloy has remanence value almost equal to Nd-low while the maximum energy product and coercivity are approximately 2.5 times higher than that of Nd-low. In view of obtained experimental results and according to aforementioned relation between structure, composition and magnetic properties of Nd-Fe-B alloys it could be stated that consequently they have also direct influence on magnetic properties of final polymer-bonded magnets. More precisely, synthesis conditions and process parameters of starting Nd-Fe-B alloys determine their nanostructure and their magnetic properties and accordingly magnetic properties of polymer-bonded magnets.

Analyzing the changes in magnetic properties, it is calculated that $(B H)_{\max }$ decreases $1.4,11.3$, and 30 times for composites with 95, 50, and $15 \mathrm{wt} \%$ of Nd-stoich particles, respectively. For composites with Nd-low particles $(B H)_{\max }$ decreases $1.3,6.4$, and 13 times for 95, 50, and $15 \mathrm{wt} \%$ of filler content, respectively. These results suggest that the nanostructure of the starting $\mathrm{Nd}-\mathrm{Fe}-\mathrm{B}$ particles has impact on magnetic properties of the composites in different manner. The decease of magnetic properties with decrease of the magnetic filler is more pronounced in the composites with stoichiometric Nd content. Therefore, for applications where the materials with high remanence are required, composites with $\mathrm{Nd}$ low content could be successfully applied. In addition, it should be noted that Nd-low alloy is economically more acceptable due to lower content of neodymium.

\section{Conclusion}

Polymer-bonded magnetic composite materials can be useful as a multifunctional elements for different applications. NdFe-B alloy as magnetic filler is identified as suitable for polymer bonding technology. Different types of starting
Nd-Fe-B alloys have different magnetic outputs reflected in properties of final composites. The obtained results show that weight amount of magnetic filler, parameters of particle synthesis as well as parameters of composite magnets production can directly change the characteristics and potential application of bonded magnets.

\section{Acknowledgment}

This work has been supported by the Ministry of Education and Science of the Republic of Serbia under Projects: III 45019, TR 34011, and ON 172037.

\section{References}

[1] O. Gutfleisch, M. A. Willard, E. Brück, C. H. Chen, S. G. Sankar, and J. P. Liu, "Magnetic materials and devices for the 21st century: stronger, lighter, and more energy efficient," Advanced Materials, vol. 23, no. 7, pp. 821-842, 2011.

[2] Y. Matsuura, "Recent development of Nd-Fe-B sintered magnets and their applications," Journal of Magnetism and Magnetic Materials, vol. 303, no. 2, pp. 344-347, 2006.

[3] M. G. Garrell, A. J. Shih, B. M. Ma, E. Lara-Curzio, and R. O. Scattergood, "Mechanical properties of Nylon bonded Nd-FeB permanent magnets," Journal of Magnetism and Magnetic Materials, vol. 257, no. 1, pp. 32-43, 2003.

[4] M. J. Wang, "The role of filler networking in dynamic properties of filled rubber," Rubber Chemistry and Technology, vol. 72, no. 2, pp. 430-448, 1999.

[5] D. Goll and H. Kronmüller, "High-performance permanent magnets," Naturwissenschaften, vol. 87, no. 10, pp. 423-438, 2000.

[6] O. Gutfleisch, "Controlling the properties of high energy density permanent magnetic materials by different processing routes," Journal of Physics D, vol. 33, no. 17, pp. R157-R172, 2000.

[7] A. Manaf, R. A. Buckley, and H. A. Davies, "New nanocrystalline high-remanence $\mathrm{Nd}-\mathrm{Fe}-\mathrm{B}$ alloys by rapid solidification," Journal of Magnetism and Magnetic Materials, vol. 128, no. 3, pp. 302-306, 1993.

[8] H. A. Davies, "Nanocrystalline exchange-enhanced hard magnetic alloys," Journal of Magnetism and Magnetic Materials, vol. 157-158, pp. 11-14, 1996.

[9] A. Manaf, R. A. Buckley, H. A. Davies, and M. Leonowicz, Enhanced Journal of Magnetism and Magnetic Materials, vol. 101, no. 1-3, pp. 360-362, 1991.

[10] O. Gutfleisch, A. Bollero, A. Handstein et al., "Nanocrystalline high performance permanent magnets," Journal of Magnetism and Magnetic Materials, vol. 242-245, no. 2, pp. 1277-1283, 2002.

[11] V. Ćosović, T. Žák, N. Talijan, A. Grujić, and J. Stajić-Trošić, "Phase composition, structure and magnetic behaviour of low neodymium rapid-quenched Nd-Fe-B alloys," Journal of Alloys and Compounds, vol. 456, no. 1-2, pp. 251-256, 2008.

[12] N. Talijan, V. Ćosović, T. Žák, A. Grujić, and J. Stajić-Trošić, "Structural and phase composition modification of nanocrystalline Nd14Fe79B7 alloy during thermomagnetic measurements," Journal of Mining and Metallurgy, Section B, vol. 45, no. 1, pp. 111-119, 2009.

[13] A. Grujić, T. Žák, N. Talijan, J. Stajić-Trošić, and V. Ćosović, "A comparative thermomagnetic study of melt-spun Nd-Fe-B 
alloys with different Nd content," Science of Sintering, vol. 41, no. 3, pp. 337-345, 2009.

[14] A. Grujic, M. Stijepovic, J. Stajic-Trošic et al., "Dynamic mechanical behaviour of polymer bonded $\mathrm{NdFeB}$ composite materials," Materials Transactions, vol. 53, no. 2, pp. 395-400, 2012.

[15] J. Mayer, L. A. Giannuzzi, T. Kamino, and J. Michael, “TEM sample preparation and FIB-induced damage," MRS Bulletin, vol. 32, no. 5, pp. 400-407, 2007.

[16] P. C. Guschl, H. S. Kim, and J. U. Otaigbe, "Effects of a Nd-FeB magnetic filler on the crystallization of poly(phenylene sulfide)," Journal of Applied Polymer Science, vol. 83, no. 5, pp. 1091-1102, 2002.

[17] X. H. Zhang, W. H. Xiong, Y. F. Li, and N. Song, "Effect of process on the magnetic and mechanical properties of Nd-FeB bonded magnets," Materials and Design, vol. 30, no. 4, pp. 1386-1390, 2009.

[18] A. S. Grujić, N. L. Lazić, N. M. Talijan et al., "Polymer-bonded magnetic materials with various Nd-Fe-B filler content," Acta Physica Polonica A, vol. 117, no. 5, pp. 859-863, 2010.

[19] A. Grujić, J. Stajić-Trošić, M. Stijepović, J. Stevanović, and R. Aleksić, "Magnetic and dynamic mechanical properties of NdFe-B composite materials with polymer matrix," in Metal Ceramic and Polymeric Composites for Various Uses, J. Cuppoletti, Ed., pp. 505-524, InTech, 2012. 

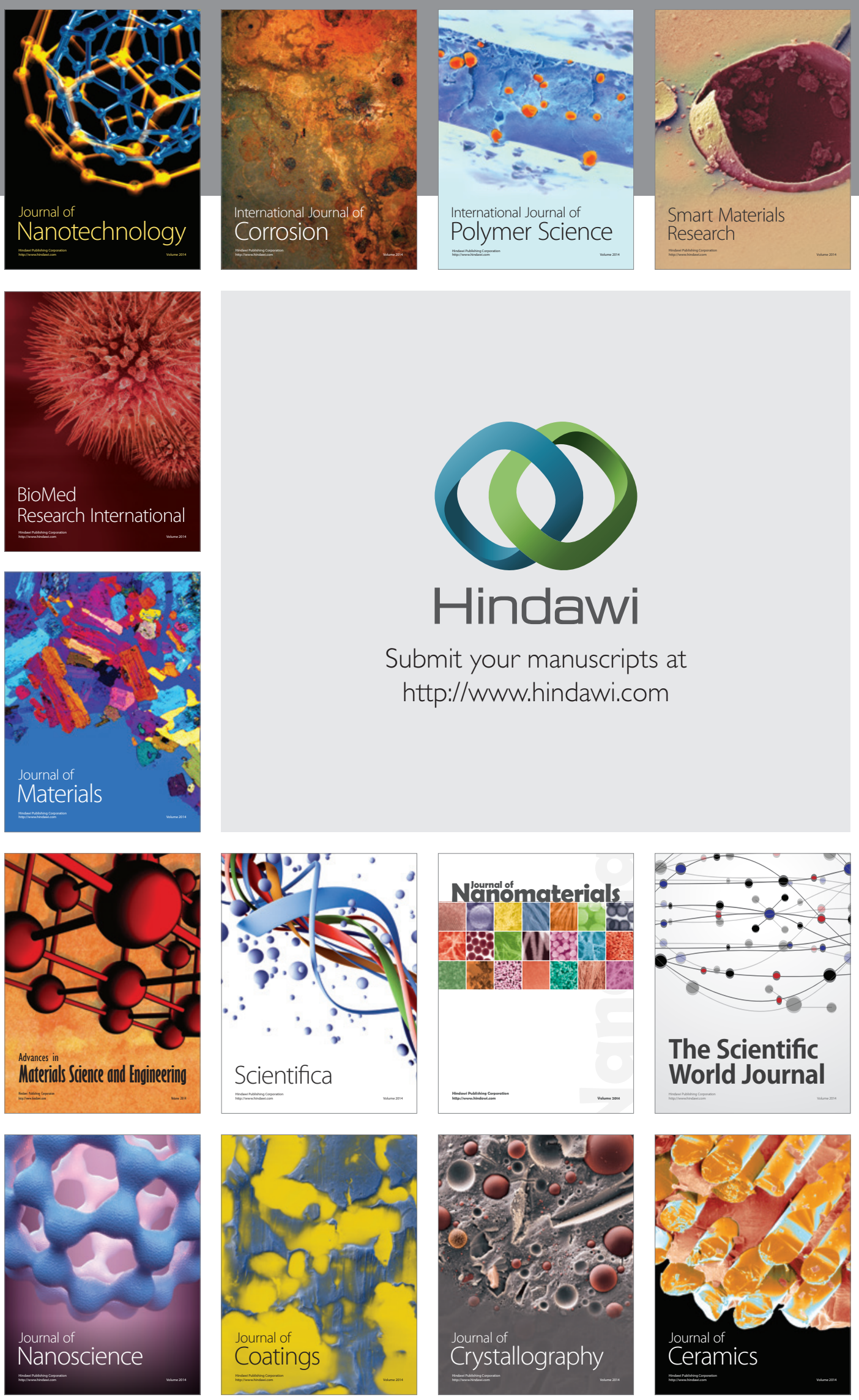

The Scientific World Journal

Submit your manuscripts at

http://www.hindawi.com

\section{World Journal}

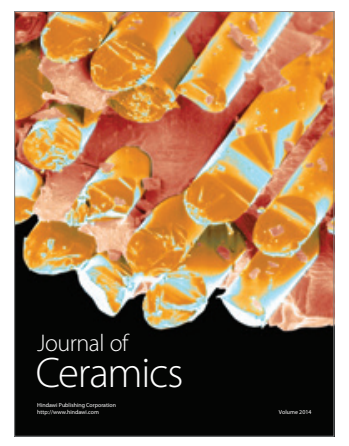

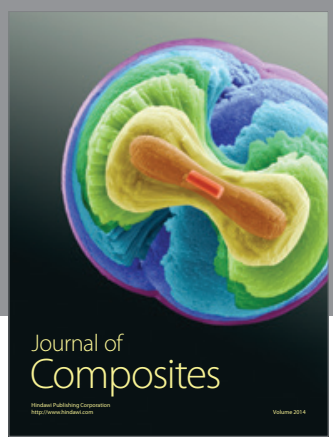
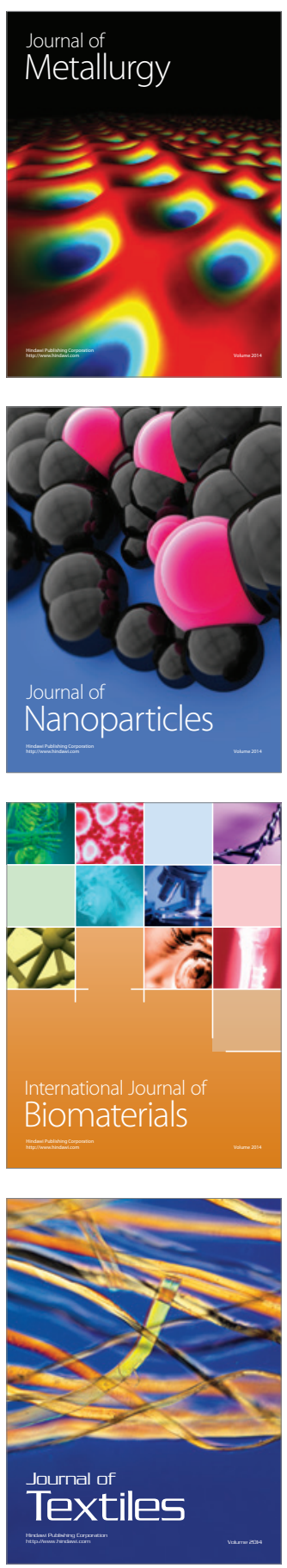